九州大学学術情報リポジトリ

Kyushu University Institutional Repository

\title{
Dynamic Analysis of Agricultural Wheel Tractor Driving on Uneven Surface under the Influences of Speed and Slope Angle
}

\section{$\mathrm{Li}$, Zhen}

Laboratory of Bioproduction Engineering, Division of Bioproduction Environmental Sciences, Department of Agro-environmental Sciences, Graduate School of Bioresource and Bioenvironmental Sciences, Kyushu University

Mitsuoka, Muneshi

Laboratory of Bioproduction Engineering, Division of Bioproduction Environmental Sciences, Department of Agro-environmental Sciences, Faculty of Agriculture, Kyushu University

Inoue, $\mathrm{Ei} \mathrm{j} \mathrm{i}$

Laboratory of Bioproduction Engineering, Division of Bioproduction Environmental Sciences, Department of Agro-environmental Sciences, Faculty of Agriculture, Kyushu University

Okayasu, Takashi

Laboratory of Bioproduction Engineering, Division of Bioproduction Environmental Sciences, Department of Agro-environmental Sciences, Faculty of Agriculture, Kyushu University

他

https://doi.org/10.5109/1467644

出版情報：九州大学大学院農学研究院紀要. 59 (2)，pp. 339-343，2014-08-29. Faculty of Agriculture, Kyushu University

バージョン :

権利関係 : 


\title{
Dynamic Analysis of Agricultural Wheel Tractor Driving on Uneven Surface under the Influences of Speed and Slope Angle
}

\author{
Zhen LI ${ }^{1}$, Muneshi MITSUOKA ${ }^{2 *}$, Eiji INOUE ${ }^{2}$, Takashi OKAYASU ${ }^{2}$ \\ and Yasumaru HIRAI ${ }^{2}$
}

\author{
Laboratory of Bioproduction Engineering, Division of Bioproduction Environmental Sciences, \\ Department of Agro-environmental Sciences, Faculty of Agriculture, \\ Kyushu University, Fukuoka 812-8581, Japan \\ (Received April 25, 2014 and accepted May 12, 2014)
}

\begin{abstract}
A dynamic three-dimensional model of a tractor travelling through a half sine wave obstacle was developed considering bouncing, pitching, and rolling motions. Compared with the case of bouncing on a level road, setting the obstacle on a sideways slope under the upper side of the forwarding tractor could stimulates a much more dangerous scenario, which may lead to tractor overturn. In this model, the tractor was considered as a rigid body, except for the tires, which were regarded as spring-damper units. The entire passing-over process was divided into four periods as done by Yamamoto and Shimada (1957), and Takeda et al. (2010) for dissecting the influence of each specific travelling period on the tractor. Basic dimensional parameters and physical properties of the objective tractor, used as input parameters in our simulation, were cited directly from the work of Takeda et al. (2010). Dynamic behavior of the tractor was described by capturing the motion of its center of gravity, which includes vertical displacement, angle, and angular acceleration for the pitching and rolling phenomena. Using the Runge-Kutta method, the desired mathematical model was numerically simulated through programming in Visual Basic Application language within Microsoft Excel. Tractor dynamic predictions were presented as factors of forward constant speed and lateral slope. The simulation results show fluctuations and increase in danger levels owing to higher velocities and steep lateral slopes. Therefore, this model enables us to explore potential overturning judgment standards.
\end{abstract}

Key words: Dynamic Response, Influence Factor, Overturn, Three-Dimensional Model

\section{INTRODUCTION}

Japan reported 123 accidental deaths caused by fourwheel-type tractors. This accounts for $49.8 \%$ of the fatal incidents due to agricultural machinery operation in 2011. Specifically, there were 94 instances of tractor overturn, i.e., $76.4 \%$ of the total number of accidents (Ministry of Agriculture, Forestry and Fisheries, 2013). Thus, it can be said that overturn-related tractor accidents have made farming operations hazardous.

For clarifying and avoiding tractor overturn, tractor motion should be focused on. Tractors with a front axle pivot are known to tip about two axes on a sideways slope. The overturning motion is then divided into phase 1 and phase 2 over time (e.g., Smith et al., 1974; Guzzomi, 2012; Baker and Guzzomi, 2013). Numerous studies on tractor dynamic behaviors have been conducted with rollovers generally classified as lateral and longitudinal. Accordingly, flat slope and sine bump are typically the corresponding excitation sources for the tractors.

\footnotetext{
Laboratory of Bioproduction Engineering, Division of Bioproduction Environmental Sciences, Department of Agroenvironmental Sciences, Graduate School of Bioresource and Bioenvironmental Sciences, Kyushu University

${ }^{2}$ Laboratory of Bioproduction Engineering, Division of Bioproduction Environmental Sciences, Department of Agroenvironmental Sciences, Faculty of Agriculture, Kyushu University

* Corresponding author (E-mail: mitsuoka@bpes.kyushu-u. ac.jp)
}

In spite of the convenience by using the virtual prototyping technologies such as CAD and CAE tools in analyzing the road-excited response, transmission efficiency and structural strength of a vehicle (Du et al., 2011; Zhu et al., 2014; Li et al., 2014), a mathematical model provides a more fundamental way for understanding the basic mechanism of vehicle performances. Pershing et al. (1969) simulated a four-wheel type tractor to obtain its transient response when passing through a half-sine bump beneath the uphill rear tire. Lagrange's equations and an energy approach were chosen for formulating a nine-degrees-of-freedom (DOF) mathematical model. A softer spring and a higher level of damping were finally recommended for improving the general ride. Davis and Rehkugler (1974) developed a 10-DOF mathematical model and used a 1/12 unpowered scale model to conduct the sideways overturning experiment. The mathematical model was verified, and it was confirmed that the model could be applied to full-sized tractors. In the case of tricycle-type tractors, the modeling of tire forces, tractor stability, and handling were studied for determining a potential view of sideways rollover and handling behaviors (Larson et al., 1976). A tractor dynamic stability index and an indicator were developed for presenting vehicle stability more intuitively with the aim of assisting operators and engineers in clearly determining the status of a tractor (e.g., Murphy et al., 1985; Zeng et al., 1989; Ahmadi, 2011; Ahmadi, 2013). Rabbani et al. (2011) derived a dynamic model of a half-track tractor for predicting the vibration characteristics with the 
dynamic spring constant and the viscous damping coefficient considered. In his model, the accelerations of the bounce, pitch, and roll motions were predicted and compared with the measured results. Apart from investigations in three-dimensional (3D) coordinates, 2D investigations have gained much attention (e.g., Homori et al., 2003; Takeda et al., 2010a, 2010b) as well.

Given that the dynamic motion of non-road vehicle systems is considerably complicated, for simplification, most tractor mathematical models restrict their applicability to small motions or other limiting assumptions beyond actual cases. Moreover, a 2D model is incapable of simultaneously describing displacement, velocity, acceleration, angle, angular velocity, and angular acceleration.

The objective of this article is, therefore, to develop a relatively precise mathematical model for describing the dynamic motions of a tractor passing over bumps on sideways slopes. Accurate geometrical relationships are addressed for formulating a nonlinear equation set that releases the constraint of small-amplitude tractor motions.

\section{DYNAMIC MODELING OF TRACTOR ON SLOPES}

For a typical tractor travelling on random terrain with a friction coefficient $\mu$, there are two types of motionsthree translational motions $(\dot{x}, \dot{y}, \dot{z})$ and three rotational motions $\left(\omega_{x}, \omega_{y}, \omega_{z}\right)$, as shown in Fig. 1. Rolling, pitching, and yawing occur owing to $\omega_{x}, \omega_{y}$, and $\omega_{z}$, respectively. Given that the forward velocity of a tractor is usually low during operations in the field, air resistance is ignored in most cases. Hence, the external forces acting on the tractor are gravity and ground reaction forces. The driving torque $\mathrm{T}_{i}$ of each wheel differs with the differential type and the drive mode. $F_{i j}$ is the decomposed force acting on the contact point of tire $i$ along the $j$ axis. Road spectrum is defined as $f(x)$ and further transformed to $f(t)$ in the time domain.

In our case, when formulating the mathematical tractor model, the following conditions were assumed in addition to neglecting air resistance:

(1) the tractor is a rigid body except for the tires, which are considered as vehicle-frame-based vertical spring-damper units.
(2) the tractor travels with a constant forward velocity; thus, the longitudinal forces are in equilibrium and yawing does not occur.

(3) the reaction forces from the road to the springdamper units are vertical with respect to the nondeformable ground surface.

(4) only the right side tires of the tractor go over the assigned half sine bump.

(5) no slipping behavior occurs.

Considering that the aim of this study is to develop a model that addresses the precise geometrical relationships of pitch and roll, the corresponding processes shown in Figs. 2 and 3 are used. Consequently, the absolute displacement of each spring-damper unit $z_{i}$ is specified in a

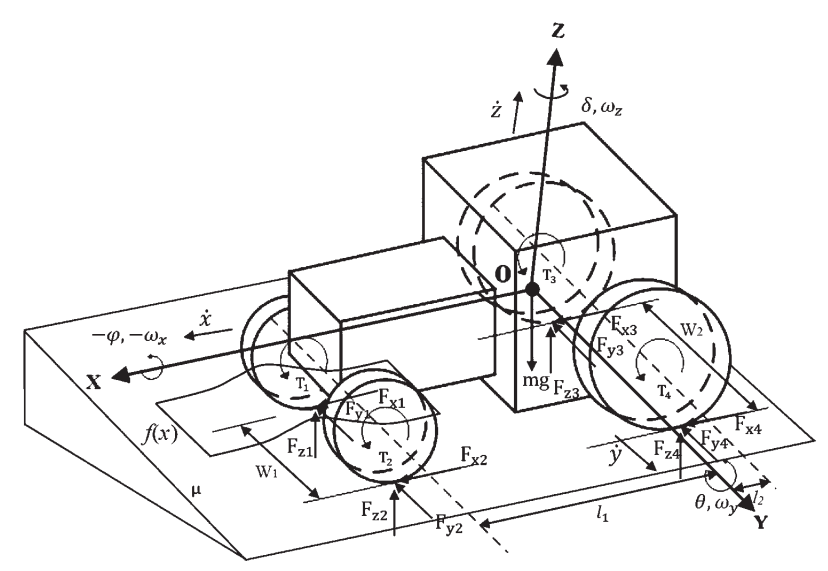

Fig. 1. General 3D tractor dynamic model on a lateral slope.

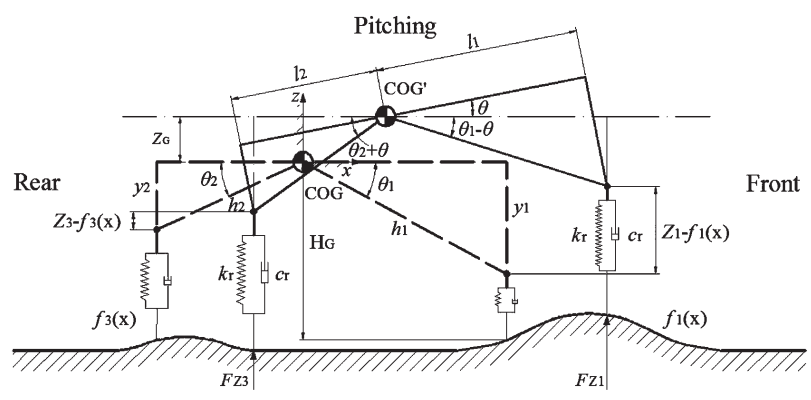

Fig. 2. Tractor pitch.

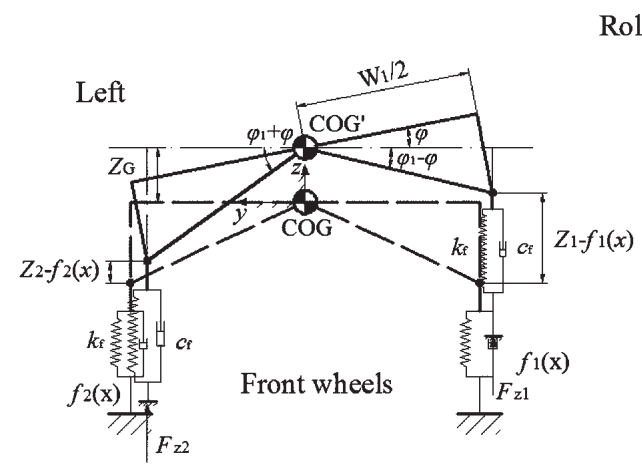

Rolling

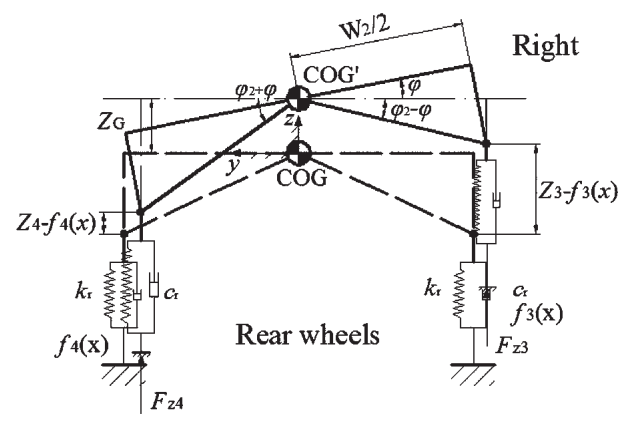

Fig. 3. Tractor roll. 
nonlinear manner. $f_{i}(x)$ represents the description function of bumps beneath a considered tire. A phased analysis of the entire passing-over process led to the adoption of four periods following Takeda et al., 2010. These are mentioned below:

1) period 1: front tire passage starts until front tire passage ends;

2) period 2: front tire passage ends until rear tire passage starts;

3) period 3: rear tire passage starts until rear tire passage ends;

4) period 4: after the end of rear tire passage.

It is obvious that Periods 1 and 3 represent sinusoidal excitation vibration, while the other two periods represent free damping. Then, the expressions of $f_{1}(x)$ and $f_{3}(x)$ depend on each period. Generally, $z_{i}$ is defined by Eqs. (1)-(4), while $f_{2}(x)$ and $f_{4}(x)$ are zero in this model.

$$
\begin{aligned}
& z_{1}=z_{G}+2 y_{1}-y_{1}(\cos \theta+\cos \phi)+l_{1} \sin \theta+w_{1} \sin \phi / 2-f_{1}(t) \\
& z_{2}=z_{G}+2 y_{1}-y_{1}(\cos \theta+\cos \phi)+l_{1} \sin \theta+w_{1} \sin \phi / 2-f_{2}(t) \\
& z_{3}=z_{G}+2 y_{2}-y_{2}(\cos \theta+\cos \phi)+l_{2} \sin \theta+w_{2} \sin \phi / 2-f_{3}(t) \\
& z_{4}=z_{G}+2 y_{2}-y_{2}(\cos \theta+\cos \phi)+l_{2} \sin \theta+w_{2} \sin \phi / 2-f_{4}(t)
\end{aligned}
$$

Where:

$z_{i}=$ Vertical displacement of the tire $i$ with respect to the ground, $m$.

$z_{G}=$ Displacement of center of gravity (COG) along $\mathrm{z}$ axis, $\mathrm{m}$.

$y_{1,2}=$ Vertical distance between COG and front, rear wheel centers, $\mathrm{m}$.

$\theta \quad=$ Pitching angle, rad

$\phi \quad=$ Rolling angle, rad .

$l_{1,2}=$ Horizontal distance between COG and front, rear axles, $m$.

$w_{1,2}=$ Width of front and rear tracks, $\mathrm{m}$.

$f_{i}(t)=$ Function of bump profile beneath the tire $\mathrm{i}$ in the time domain, $m$.

Based on the aforementioned conditions, an equation set describing a 3-DOF system is presented as follows. The coordinate o-xyz used here is space-fixed and overlaps with the vehicle-fixed coordinate at the start of the analysis.

$$
\begin{aligned}
m \ddot{z}_{G} & =F_{z 1}+F_{z 2}+F_{z 3}+F_{z 4}-m g \cos \alpha \\
I_{x} \ddot{\phi} & =\left[\frac{w_{1}\left(F_{z 1}-F_{z 2}\right)}{2}+\frac{w_{2}\left(F_{z 3}-F_{z 4}\right)}{2}\right] \cos \phi \\
& +\left[y_{1}\left(F_{z 1}+F_{z 2}\right)+y_{2}\left(F_{z 3}+F_{z 4}\right)\right] \sin \phi+f H \\
l_{y} \ddot{\theta} & =\left(F_{z 1}+F_{z 2}\right)\left(l_{1} \cos \theta+y_{1} \sin \theta\right) \\
& -\left(F_{z 3}+F_{z 4}\right)\left(l_{2} \cos \theta+y_{2} \sin \theta\right) \\
F_{z i} & =-k_{i} z_{i}-c_{i} \dot{z}_{i}
\end{aligned}
$$

Where:
$F_{z i}$, Vertical reaction force from ground to tire $i, \mathrm{~N}$.

$k_{i}$, Spring constant, $\mathrm{N} / \mathrm{m}$.

$c_{i}$, Damper Constant, Ns/m.

$m g$, Gravitational force acting on tractor, N.

$\alpha$, Slope angle, rad.

$I_{x, y}$, Moment of inertia around $\mathrm{x}, \mathrm{y}$ axes, $\mathrm{kg} \cdot \mathrm{m}^{2}$. $f$, lateral friction force, $\mathrm{N}$.

\section{RESULTS AND DISCUSSION}

Forward velocity and slope angle were considered as factors influencing bouncing, pitching, and rolling behav-

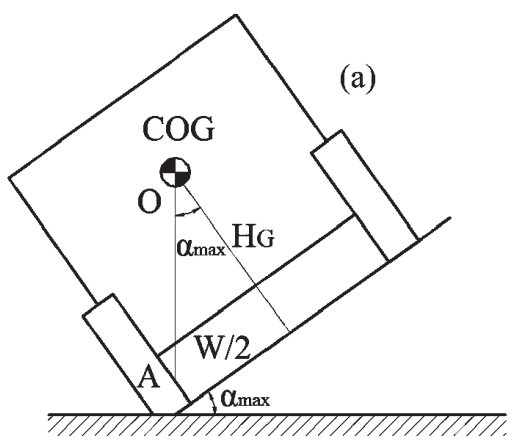

(b)

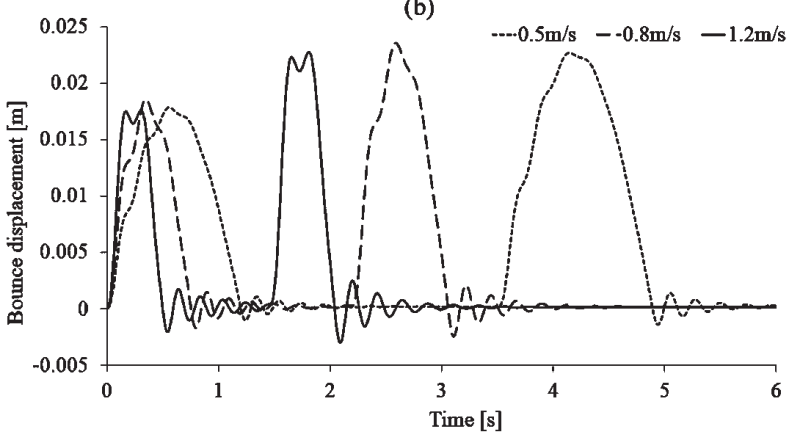

(c)

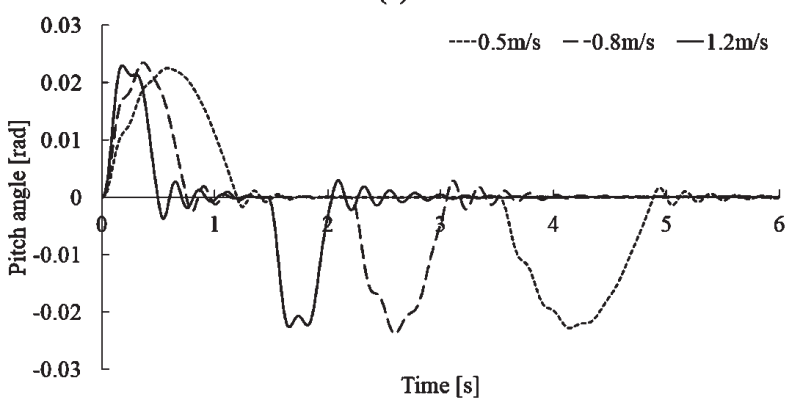

(d)

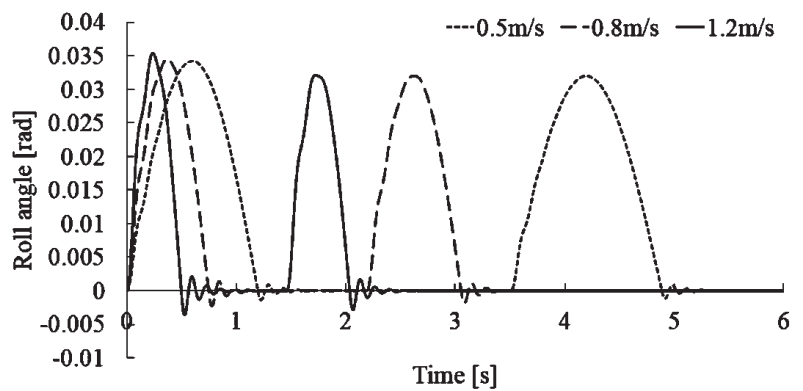

Fig. 4. Critical lateral angle of static overturn (a); and effect of speed on bounce displacement (b), pitch angle (c), and roll angle (d) at the COG. 
iors. The standard condition was set as follows: forward velocity of $0.5 \mathrm{~m} / \mathrm{s}$, slope angle of $10^{\circ}$, and bump height of $0.08 \mathrm{~m}$. Input parameters, i.e., tractor geometrical dimensions, physical properties, and bump profile were cited from Takeda et al. (2010).

For a static-state tractor on lateral slope, as shown in Fig. 4(a), sideways overturn occurs as soon as the COG passes over the vertical line OA, coming up with the critical slope angle $\alpha \max =\mathrm{W} / 2 \mathrm{HG}$, where $\mathrm{W}$ is the wheel track and HG is the COG height. The rear wheel track (narrower by $13 \mathrm{~cm}$ compared with the front wheel track) was considered as $\mathrm{W}$ for limiting the tractor to a safer condition. Consequently, $\alpha$ max and the limit rolling angle for the standard case were $40.56^{\circ}$ and $26.59^{\circ}$, respectively. Because lateral overturn is the first concern of this study, COG motion and position are important. These predictions were made using the RungeKutta method and VBA programming. Figures 4(b)-(d) show the effect of forward speed on $z, \theta$, and $\phi$.

Figure 4(b) shows the increase in the COG vertical displacement during Period 3 for each speed. The increase percentages are $30.4,23.1$, and 29.6 for velocities of $0.5 \mathrm{~m} / \mathrm{s}, 0.8 \mathrm{~m} / \mathrm{s}$, and $1.2 \mathrm{~m} / \mathrm{s}$, respectively. Both Figs. 4(b) and (c) show the fluctuations that occur when the right side tires nearly reach the top of the bump, thus signifying the transient instabilities of vertical bounce and pitch as the speed increases. However, the rolling angles shown in Fig. 4(d) indicate relatively smooth transitions at those moments under speeds of $0.5 \mathrm{~m} / \mathrm{s}$ and $0.8 \mathrm{~m} / \mathrm{s}$. In addition, Fig. 4(d) shows that the rolling angle was greater in Period 1 compared with Period 3, and that a higher speed results in a greater maximum rolling angle.

Considering the lateral slope angle as another factor,

(a)

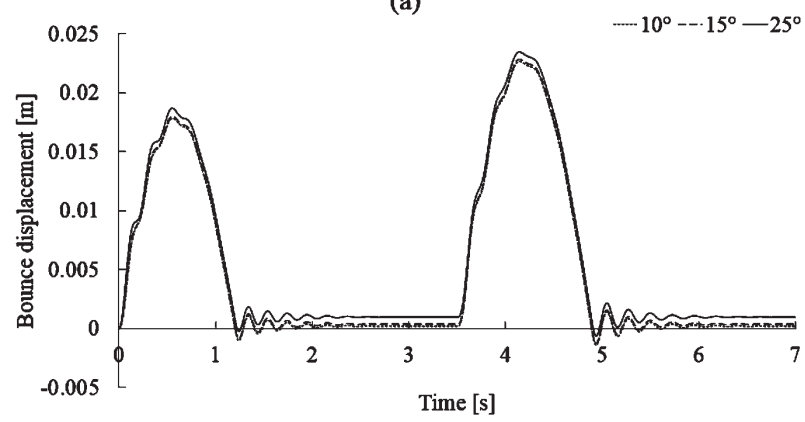

(b)

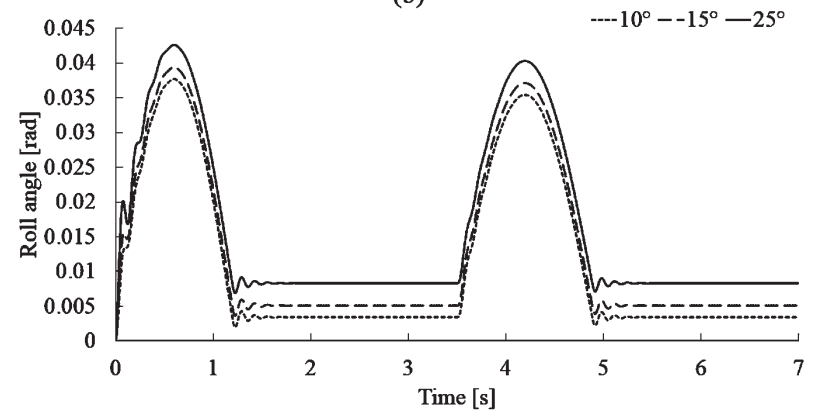

Fig. 5. Effect of lateral slope angle on bounce displacement (a), and roll angle (b). parameters of $10^{\circ}, 15^{\circ}$, and $25^{\circ}$ were selected. As shown in Fig. 5, the increase in slope angle has small influence on tractor bounce displacement, while an apparent effect was observed in terms of roll angle. The static roll angle describing the initial tractor orientation rises as well as the maximum roll angle in both periods 1 and 3. Also, the response of tractor roll motion for a $25^{\circ}$ slope fluctuates intensively compared to parameters of $10^{\circ}$ and $15^{\circ}$. In addition, there is no obvious difference detected in tractor pitch motion for slope angle series.

\section{CONCLUSIONS}

The motion and position of the COG were predicted using the developed 3D tractor dynamic mathematical model with relatively precise geometrical relationships. Tractor forward velocity and lateral slope angle were considered as factors.

The results show that $z$ and $\theta$ fluctuated when the tractor was at the top of the bump under the speed of $1.2 \mathrm{~m} / \mathrm{s}$. For a given case, a larger displacement occurs in Period 3 than in Period 1, whereas the reverse is true for the rolling angle. In addition, higher speeds results in greater rolling angles. Furthermore, increasing the lateral slope angle significantly affect dynamic tractor roll motion and initial tractor orientation, while the influence is minute on bounce displacement. Besides, the change in slope angle nearly has no effect on tractor pitch motion.

\section{ACKNOWLEDGEMENTS}

We would like to express sincere appreciation to the China Scholarship Council for financial support.

\section{REFERENCES}

Ahmadi, I. 2011 Dynamics of tractor lateral overturn on slopes under the influence of position disturbances (model development). J. Terramechanics, 48(5): 339-346

Ahmadi, I. 2013 Development of a tractor dynamic stability index calculator utilizing some tractor specifications. Turk. J. Agric. For., 74(1): 203-211

Baker, V. and Guzzomi, A. L. 2013 A model and comparison of 4-wheel-drive fixed-chassis tractor rollover during Phase I. Biosystems Eng., 116(2): 179-189

Davis, D. C. and Rehkugler, G. E. 1974 Agricultural wheel-tractor overturns. Trans. ASAE, 17(3): 477-488

Du, Y. F., Zhu, Z. X., Mao, E. R., Song, Z. H., Gao, J. M. and Zhu, K. G. 2011 Simulation on small-scale corn harvester for hilly area based on ADAMS. Transactions of the Chinese Society for Agricultural Machinery, 42(SUPPL.): 1-5

Guzzomi, A. L. 2012 A revised kineto-static model for Phase I tractor rollover. Biosystems Eng., 113(1): 65-75

Homori, H., Sakai, K., Sasao, A. and Sibusawa, S. 2003 2D dynamics simulator for impact oscillators analysis of tractor-implement system. J. JSAM, 65(1): 85-90

Larson, D. L., Smith, D. W. and Liljedahl, J. B. 1976 The dynamics of three-dimensional tractor motion. Trans. ASAE, 19(1): 195-200

Li, F. Q., Liu, S. R., Mao, E. R., Xie, B. and Zhang, L. X. 2014 Structural analysis and optimization of combine harvester frame. Applied Mechanics and Materials, 490-491: 629-632

Murphy, D. J., Beppler, D. C. and Sommer, H. J. 1985 Tractor sta- 
bility indicator. Applied Ergon., 16(3): 187-191

Pershing, R. L. and Yoerger, R. R. 1969 Simulation of tractors for transient response. Trans. ASAE, 12(5): 715-719

Rabbani, M. A., Tsujimoto, T., Mitsuoka, M., Inoue, E. and Okayasu, T. 2011 Prediction of the vibration characteristics of halftrack tractor considering a three-dimensional dynamic model. Biosystems Engineering, 110(2): 178-188

Report on fatal farming accidents that happened in 2011 (in Japanese, 5 April 2013). Ministry of Agriculture, Forestry and Fisheries of Japan. Available from http://www.maff.go.jp/j/ seisan/sien/sizai/s_kikaika/anzen/pdf/2r23_gaiyou.pdf

Smith, D. W., Perumpral, J. V. and Liljedahl, J. B. 1974 The kinematics of tractor sideways overturning. Trans. ASAE, 17(1): $1-3$

Takeda, J., Shimada, M., Kikuchi, Y., Nakano, M., Okada, S., Hiroma,
T. and Torisu, R. 2010a dynamic behaviors of farm tractor passing over an obstacle (part 1). Journal of the Japanese Society of Agricultural Machinery, 72(5): 457-463

Takeda, J., Shimada, M., Kikuchi, Y., Nakano, M., Okada, S., Hiroma, T. and Torisu, R. 2010b Dynamic behaviors of farm tractor passing over an obstacle (part 2). Journal of the Japanese Society of Agricultural Machinery, 72(5): 464-470

Zeng, D. C., Zhu, Y. H. and Zhou, Y. M. 1989 A mathematical model for sideways overturning performance of tractor and trailer combinations. J. Terramechanics, 26(3-4): 193-200

Zhu, Z. X., Li, Z., Xie, B. and Mao, E. R. 2014 Virtual prototyping analysis on gear assembly of the power train for a large-scale combine harvester. Applied Mechanics and Materials, 441: 635-640 